\title{
Nursing students' perceived stress and influences in clinical performance
}

\author{
Laila M. Akhu-Zaheya ${ }^{1 *}$, Insaf A. Shaban ${ }^{2}$, Wejdan A. Khater ${ }^{1}$ \\ 1 Jordan University of Science and Technology \\ ${ }^{2}$ Al al-Bayt University \\ *Corresponding authorE-mail: lailanurse@ust.edu.jo
}

\begin{abstract}
Background: It is known that stress related to clinical training among nursing students could contribute to many physical and mental problems. However, little empirical evidence about the influence of stress in nurse students' clinical performance

Objective: The objective of this study was to assess the association between perceived stresses, stress related factors, and students' clinical performance.

Method: Using the perceived stress scale, 539 Jordanian nursing students from 2 public universities in Jordan participated in the study. Results: The results showed that the mean of stress perceived by students was 45.9. Students' assignment were perceived as the main source of stress $(M=10.7, S D=4.5)$ followed by stress related to patients' care $(M=10.5, S D=5.5)$ and stress from teachers and nursing staff $(\mathrm{M}=9.6, \mathrm{SD}=5.3)$. The lowest source of stress is from students' lack of professional knowledge and skills $(\mathrm{M}=3.96 ; \mathrm{SD}=2.8)$. The mean of students' clinical performance is $73.4 \%$. Students' perceived stress has a significant negative correlation with students' clinical performance $(r=-.09 ; p<.05)$. The results also showed significant negative correlation between stress related to lack of professional knowledge and skills, and stress related to patient care and students' clinical performance.

Conclusion: This study expanded on students' stress in clinical settings, and warrants further research in assessing its impact on their performance. Teachers should be aware of and help students to overcome and cope with said stress related factors in the clinical settings effectively.
\end{abstract}

Keywords: Nursing Students, Nursing Education, Stress, Clinical, Practice.

\section{Introduction}

Stress is defined as "a particular relationship between the person and the environment that is appraised by the person as taxing and/ or exceeding his or her resources and endangering his or her wellbeing"(Lazarus \& Folkman 1984 , P.19). Stress is the way we respond to stressors, defined as events or issues that make us aggravated, exasperated, or infuriated. The differences in the way individuals perceive stressful situations and cope with these stressful situations account for why some individuals suffer more than others. An event which could be demanding and stressful for one person, could have minimal to no effect on another person's life, and therefore, negatively or positively affects their health, wellbeing, and their way of working (Lazarus \& Folkman 1984 ).

Nursing students encounter different stressors, such as those related to their academic studies (e.g. assignment, grades, exams); clinical training stressors (e.g. lack of professional knowledge and skills); in addition to external stressors (e.g. personal issues, daily life, and financial stressors) (Jimenez et al. 2010, Alzayyat \& AlGamal 2014, Khater et al. 2014). Indeed, it is widely acknowledged that nursing students find clinical training stressful (Burnard et al. 2007)

Stress in the clinical setting is one of the strains that accompanies a demand perceived to be either positive (Behere et al. 2011) or negative - depending on its appraisal - which could lead to positive (e.g. being a motivator) or negative consequence (e.g. somatic symptoms) (Burnard et al. 2007). It has been reported that nursing students experience higher levels of stress, as well as more physical and psychological symptoms compared to students from other health-related disciplines (Deary et al. 2003, Pulido-Martos et al. 2012, Burnard et al. 2007).

Most of the studies of clinical-related stress focused on psychological and emotional response to stress (Watson et al. 2008, Luo \& Wang 2009). In a systematic review of 23 quantitative studies conducted in different countries - mostly Western countries (Albania; Australia; Chili; China; England; Ireland; Iran; Scotland; South Africa; Spain; USA) - the authors reported that there were only four studies which looked at the relation between nursing students' perceived stress and other predictors such as coping, burnout, and self-esteem (Pulido-Martos et al. 2012). In addition, because most studies regarding nursing students' stress were conducted in Western countries, it has been recommended that more cross-cultural studies, in different countries, are necessary (Lambert \& Lambert 2001). Specifically in Jordan, few studies were conducted concerning nursing students' stress and clinical stress-related factors (Abu Tariah \& Al-Sharaya 1997, Alzayyat \& Al-Gamal 2014, Khater et al. 2014, Shaban et al. 2012). Moreover it is unclear whether nursing students' perceived stress in clinical training has an impact on nursing students' clinical performance. Our study aims at learning whether there is a relationship between nursing students' perceived stress during clinical training and their clinical performance, as well as the connection between the stress- 
related factors and students' clinical performance. There is little empirical evidence about the influence of stress in nursing students' clinical performance (Pitt et al. 2012). The findings from our study would benefit various parties. It would help the universities in designing and conducting necessary programs in order for the students to more effectively manage stress, so that they may improve their academic performance. Also, it would guide the adoption of suitable teaching and learning methods, so that stressrelated clinical practices will be at a minimum. Understanding nursing students' professed stress in the clinical practice would provide greater insight so as to develop an effective clinical teaching strategy in nursing education.

\section{Literature review}

Using different databases including CINAHL, MEDLINE, PubMed, a review of the literature was conducted. The inclusion criteria were: readily available studies (quantitative and qualitative), spanning the years 2005 to 2014 anticipated to be helpful in the analysis. The search was limited to English-language journals using the following keywords: nursing students, stress, nursing education, clinical and practice. In addition, by examining related references in the identified studies, the researchers conducted a secondary literature search, although many were before 2005 in order to find the relevant information and get a clear picture about the topic.

Stress is especially crucial in education because it has the potential to impede human learning and functioning, and may lead to attrition (Yucha et al. 2009). Further, current studies on nursing students' clinical teaching suggest that students are overwhelmed in their clinical teaching to the point where it could influence their safety (Killam et al. 2013). Nursing students, at all undergraduate educational levels programs, (Diploma, Associates, Baccalaureate) report high levels of stress and anxiety within the clinical learning environment (Carlson et al. 2003, Elliott 2002, Hayden-Miles 2002, Sharif \& Masoumi 2005). In addition, nursing students experienced and reported stress as they progressed through their nursing programs (Bremner et al. 2008, Shaban et al. 2012, Jimenez et al. 2010). This stress is undoubtedly related to the intensity and complexity of nursing programs, including the large amounts of time spent learning in clinical settings (Jimenez et al. 2010).

Clinical training is always integral part of nursing programs. The clinical portion of nursing education would integrate the affective (knowing) and psychometric (doing, skills) aspect of learning (Sharif \& Masoumi 2005). Clinical training, in most nursing programs, is considered to be the largest part of education among nursing students. In a descriptive correlation study by Beck and Srivastava (1991) including 94 second, third and fourth year nursing students; the students reported that the clinical experience was by far, the most nerve-wracking part of the nursing program. This is congruent with a study by Timmins and Kaliszer (2002), who included third year students at the diploma program.

Stress could affect both an individual's ability to learn and their memory (Kaplan \& Sadock 2000). Although an optimal level of stress can enhance learning ability (Kaplan \& Sadock 2000), too much stress can cause physical and mental health problems (Pulido-Martos et al. 2012, Deary et al. 2003, Burnard et al. 2007) and may affect the academic achievement of students (Choi et al. 2007, Elliot et al. 2005, Hofer 2007, Robbins et al. 2006, Trautwein et al. 2006, Was et al. 2006). It is stated that "High stress and anxiety impede concentration, memory, and problemsolving ability, which in turn, adversely affect academic performance and learning" (Beddoe \& Murphy 2004, P. 305)

To date, there has been relatively little research looking at the specific effects of perceived stress concerning the clinical performance of nursing students. Of the research that does exist, the findings are rather ambiguous. Some studies have demonstrated impaired performance under acutely stressful conditions (LeBlanc et al. 2008, Floyd 2010, Cheung \& Au 2011) while others have shown improved performance (LeBlanc et al. 2008). We propose that higher stresses would be associated with a lesser degree of clinical performance.

\section{Methods}

\subsection{Design}

We chose a descriptive, correlational, cross-sectional design since we are seeking to describe the relationships among the variables in one point of time. We assessed the correlation between nursing students' perceived stress, and their clinical performance, as well as the correlation between students in the clinical training stresses and the clinical performance of nursing students enrolled in two different nursing schools in North Jordan.

\subsection{Participants and setting}

The target population of this study is Bachelor nursing students who are enrolled in clinical courses. Participants in this study were recruited from the four-year undergraduate Bachelor of Nursing program at two public universities in North Jordan. All Baccalaureate-nursing students in their second, third, and fourth years were eligible to participate in the current study, since they had already started their clinical practicum. A total of 539 nursing students participated in the study

\subsection{Ethical issues}

The Institutional Review Board (IRB) at both universities approved the present study. Within the clinical setting, according to the students' area of practice, they were approached by the clinical teachers. The clinical teachers informed students of the study's purpose and its outcomes. Written Informed consent was obtained through the provision of an information cover letter which outlined the confidentiality of the data. Participants were assured that participation in the study was voluntary, and would in no way, affect their grade. Upon their agreement, research assistants, who were trained in data collection, distributed the questionnaire. Data collected were stored in a manner compliant with data-protection. The researchers had no conflict of interest.

\subsection{Research instrument}

The study utilized self-reported surveys, composed of demographic data and perceived stress scale (PSS). Demographic data included: age, gender, and years of education, interest in nursing and previous nursing experience. Perceived Stress Scale (PSS) was developed by Sheu et al. (1997) to assess the degree of stressors that occurred during clinical practices and types of stressful events as perceived by nursing students. It consists of 29 items of 5-point Likert-type scale, (0: never - 4: always) with items grouped into six factors, related to the source of the stress. The six factors included stress from taking care of patients ( 8 items), stress from teachers and nursing staff (6 items), stress from assignments and workload (5 items), stress from peers and daily life (4 items), stress from lack of professional knowledge and skills ( 3 items), and stress from clinical environment (3 items). The total score ranged from 0-116. A lower score indicated a lower degree of stress, while the higher score indicated a higher degree of stress. Reliability of the instrument revealed Cronbach's alpha of .89 (Chan et al. 2009, Sheu et al. 2002, Sheu et al. 1997). In our current study, the reliability revealed Cronbach's alpha of .90 .

Students' clinical performance constitutes of their clinical assignment, logs, care plan, and direct patients care. Students' clinical performance was measured by students' final clinical course grade at the conclusion of the semester, of the course the student was enrolled in at the time data collection. The students' final clinical course grade was obtained from the Admission and Registration Department at both universities. 


\subsection{Data collection}

The study was conducted simultaneously in both universities between September and November 2010, taking into consideration the students' examination period. The students approached their clinical area. Questionnaires were distributed at the end of the clinical day by the research assistant, which provided the students with descriptions of the study's purposes and its outcomes. Students who agreed to participate were required to sign consent forms, and were encouraged to ask for any clarifications, if needed. The students were assured that their answers would not affect their course grade.

\subsection{Analysis}

Data were analyzed using the Statistical Package for Social Science (SPSS) for Windows Version 17. Descriptive statistics, appropriate to the level of measurement, were used to describe the study's variables. Pearson correlation was used to assess the association between students' perceived stress and their clinical performance (grades in the clinical course). Independent t-tests were used to assess the mean differences between students' gender, in terms of academic performance.

\section{Results}

A total of 539 nursing students participated in the study from both universities. The majority of the students were female students $358(66.4 \%)$ and only181 (33.6\%) students were male. The students' ages ranged between 19 and 24, with a mean of 20.7 year $(\mathrm{SD}=1.12)$. There were $228(42.3 \%) ; 169(31.4 \%)$ and 142 (26.3\%) in their second, third, and fourth year of their study, respectively. The highest number of participants was in the Adult Health Nursing I $(n=174,32.3 \%)$. Table 1 shows the demographic characteristics of the participants.

Table 1: Students Demographic Characteristics

\begin{tabular}{|l|l|c|c|}
\hline \multicolumn{2}{|c|}{ Variables } & Frequency & $\%$ \\
\hline Gender & & & \\
& - Male & 181 & $33.6 \%$ \\
& - Female & 358 & $66.4 \%$ \\
\hline \multirow{3}{*}{ Year of Study } & - Second Year & 228 & $42.3 \%$ \\
& - Third Year & 169 & $31.4 \%$ \\
& - Forth Year & 142 & $26.3 \%$ \\
\hline \multirow{5}{*}{ Course Enrolled } & - Adult Health Nursing I & 174 & $32.3 \%$ \\
& - Adult Health Nursing II & 103 & $19.1 \%$ \\
& - Pediatric & 41 & $7.6 \%$ \\
& - Maternity & 84 & $15.6 \%$ \\
& -Advanced Adult Nursing & 51 & $9.5 \%$ \\
& - Training & 86 & $16.0 \%$ \\
\hline Instructor Gender & - Male & 148 & $27.1 \%$ \\
& - Female & 391 & $72.9 \%$ \\
\hline \multirow{2}{*}{ N=539 } & \multicolumn{2}{|l}{}
\end{tabular}

Students' perceived stress was ranged between 2 and 99 with a mean of $45.9(\mathrm{SD}=17.8)$, however, there are no significant gender differences, in terms of stress perceived. Students' assignments were perceived as the main source of stress $(M=10.7, S D=4.5)$ followed by stress related to patients' care $(\mathrm{M}=10.5, \mathrm{SD}=5.5)$; and stress from teachers and nursing staff $(M=9.6, S D=5.3)$. The lowest source of stress is from students' lack of professional knowledge and skills $(\mathrm{M}=3.96 ; \mathrm{SD}=2.8)$. However, there are no significant gender differences, in terms of stress-related factors. The mean of students' clinical performance is $73.4 \%(\mathrm{SD}=8.6 \%)$ and a range between $42-93 \%$. There are significant differences between female $(M=75.5 ; S D=7.9)$ and male students $(M=69.2$; $\mathrm{SD}=8.4)$ in their clinical performance $(t=-8.4 ; p<.05)$. Students' perceived stress has a significant negative correlation with students' clinical performance ( $r=-.09 ; p<.05)$.

The correlation between stress related factors and clinical performance showed significant negative correlation between stress related to students' lack of professional knowledge and skills ( $r=$
$-.11 ; p<.05)$ and stress related to patient care and students' clinical performance $(r=-.13 ; p<.05)$.

\section{Discussion}

Nursing is incredibly stressful profession (Jones \& Johnston 2000, Bennett et al. 2001). The aim of our study was to assess the association between perceived stresses, stress related factors and students' clinical performance, as well as looking to gender differences in terms of stress related factors and clinical performance. Stress in nursing students is more evident at the training period (Deary et al. 2003, Burnard et al. 2007). Clinical components were found to be more stressful than academic elements for nursing students in different countries (Burnard et al. 2007). In our current study, we found that perceived stress of nursing students in the clinical setting is moderate. Although our study includes nursing students at different levels, the results are consistent with a previous study conducted among nursing students, at their initial clinical practice that students perceived clinical training as stressful (Shaban et al. 2012). Results are also consistent with previous studies conducted among nursing students within different cultures (Chan et al. 2009, Sheu et al. 2002, Jimenez et al. 2010).

It is appealing that the factors, which appear to be more stressful in the clinical setting, are students' assignments, stress related to patients' care and stress related to teachers and nursing staff. This is congruent with previous studies that used PSS (Sheu et al. 2002, Jimenez et al. 2010, Chan et al. 2009). Stress related to lack of knowledge and skills was determined to be one of the highest sources of stress in a previous study (Jimenez et al. 2010), which contradicts our study's results. In our faculties, including all courses, nursing students spend 2 weeks at the lab as a method of preparation before going to the hospital. During the aforementioned preparatory weeks, students are taught the most common cases and procedures - depending on the course - they would face. In our study however, we found that there was a negative correlation between the lack of students' professional knowledge and skills and students' clinical performance. This is also congruent with previous literature (Hamill 1995, Mahat 1998, Oermann \& Lukomski 2001).

In clinical training, students' grades are partially based on their skills and knowledge. Students sometimes have an incredible fear of being observed by the faculty (Kim 2003), especially in the presence of others, and express fear and uncertainty when performing their skills. Another important issue, is stress related to patients' care and its influence on the students' clinical performance, which could be related to students' fear of making mistakes (Kim 2003).

We also discovered that students' mean clinical performance is considered "good", which is based on the grading criteria at the university. The course grading system includes a grade of Excellent (A), Very Good (B); Good (C), Acceptable (D), Weak (E), and Fail (F) for a score of "90-100"; "80-89"; "70-79"; "60-69"; "50-59"; and "less than 50" respectively. Our students strive to do their absolute best in order to get the highest grade, even if this subsequently increases their levels of stress. These findings would explain our results of having negative correlation between stress and performance, and this supports our hypothesis that higher stresses are associated with lesser clinical performance. In our culture, the grade is a major concern for the students and their significant others (family, relatives, friends, and neighborhood). In addition, many hospitals are hiring students' based on the graduate score, and sometimes, they would look at students' grades at specific courses such as Medical Surgical and Critical and Training courses.

Female students experienced higher levels of stress than male students (Tully 2004). In our study, and although the number of female students were slightly more than male students, there were no significant gender differences in terms of stress perceived and stress related factors. However, there were a significant gender differences in terms of clinical performance. It is argued that male 
and female students do, in fact, learn differently from one another and this influences their achievement outcomes (de Saintonge \& Dunn 2001). Higher female students' achievement could in fact be due to non-academic factors, such as the level of students' selfesteem, and economic factors that impacted the student (Hass et al 2004). In addition, with the economic and financial constraints, in our culture, many male students are working while studying to fulfill economic needs. Moreover, nursing, historically, tends to be a female profession, where females are more expected to enter the profession, with motivation and passion for nursing, while male students are more liable to enter the profession as a way for quick employment and money making.

\section{Implications}

Although there are differences in some factors related to stress; our results confirmed previous studies' results regarding students' experience of stress during clinical practice. Understanding factors contributing to students' stress and its impact on students' performance would help in reforming the education curriculum to empower students in the clinical setting and would help the teachers in dealing with students' concerns.

This study expands on knowledge of students' stress in clinical settings and warrants further intervention from both clinical teachers and clinical staff. Findings indicate that nursing students have a significant amount of stress among nursing students that may potentially lead to poor academic achievement. There are several studies of perceived stress among nursing students in different countries; however few studies provided intervention to eliminate this stress. Results of this study imply the need for a strategy to enhance students' confidence, especially when it comes to taking care of patients. It is necessary for nursing educators to take measures in order to provide a supportive environment so as to reduce nursing students' stress (Singh et al. 2013). Incorporating simulators in the nursing education is one of the supportive measures that would decrease students' stress (Oberleitner et al. 2011). Hutchinson \& Goodin (2013) suggested establishing a caring transaction in order to lessen the impact of anxiety on student learning. Caring transaction is a vehicle for nursing faculty to assist students in finding meaning to the anxiety, and guide students to engage in self-care using the practice of mindfulness and reflection (Hutchinson \& Goodin, 2013, p 22).

\section{Limitations}

Our study revealed results that would be very beneficial for nurses and the nursing profession. However, there are some limitations that should be taken into consideration. The evaluation criteria used varies between courses. Also, it could be applied differently by varying faculty, and could therefore be affected by the subjectivity of the faculty. Female performance was more than male, although there was no significant difference in stress, which could be related to the course itself, students enrolled in; however, it was not possible to look to these differences, because of the unequal number of male and female students within the courses.

\section{Conclusion}

It is a consistent conclusion that nursing students are confronted with stressors in the clinical setting. Instructors should be sensitive to these stressors and should help students to cope with them, which would lead to a much better quality of work. Understanding factors contributing to students' stress and its impact on students' performance would help in reforming the education curriculum thereby empowering students in the clinical setting and would help the teachers in dealing with students' concerns. Further studies should take into consideration both gender stresses and performance differences in different courses.

\section{Acknowledgement}

This paper was funded by the Deanship of Research / Jordan University of Science and Technology. The authors would like to acknowledge the students who took part in this study. The authors also gratefully acknowledge the invaluable contribution of Manar Yacoub Saleh, student at University of Houston/ English Literature/Political Science in Editing.

\section{References}

[1] Abu Tariah, H. \& Al-Sharaya, H. (1997). Stresses Reported by Second Year Nursing Students. Nurse Educator, 22, 33. http://dx.doi.org/10.1097/00006223-199709000-00004.

[2] Alzayyat, A. \& Al-Gamal, E. (2014). A review of the literature regarding stress among nursing students during their clinical education. International Nursing Review, 61, 406-415. http://dx.doi.org/10.1111/inr.12114.

[3] Beck, D. \& Srivastava, R. (1991). Perceived level and source of stress in baccalaureate nursing students. Journal of Nursing Education, 30, $127-132$.

[4] Abu Tariah, H. \& Al-Sharaya, H. (1997). Stresses Reported by Second Year Nursing Students. Nurse Educator, 22, 33. http://dx.doi.org/10.1097/00006223-199709000-00004.

[5] Alzayyat, A. \& Al-Gamal, E. (2014). A review of the literature regarding stress among nursing students during their clinical education. International Nursing Review, 61, 406-415. http://dx.doi.org/10.1111/inr.12114.

[6] Beck, D. \& Srivastava, R. (1991). Perceived level and source of stress in baccalaureate nursing students. Journal of Nursing Education, 30, $127-132$.

[7] Beddoe, A. E. \& Murphy, S. O. (2004). Does mindfulness decrease stress and foster empathy among nursing students? J Nurs Educ., 43, 305-12.

[8] Behere, S. P., Yadav, R. \& Behere, P. B. (2011). A comparative study of stress among students of medicine, engineering, and nursing. Indian journal of psychological medicine, 33, 145-148. http://dx.doi.org/10.4103/0253-7176.92064.

[9] Bennett, P., et al. (2001). Stress in nurses: coping, managerial support and work demand. Stress and Health, 17, 55-63. http://dx.doi.org/10.1002/1532-2998(200101)17:1<55::AID SMI879>3.0.CO;2-2.

[10] Bremner, M., Aduddell, K. \& Amason, J. (2008). Evidence-based practices related to the human patient simulator and first year baccalaureate nursing students' anxiety. Online Journal of Nursing Informatics, 12, 10p.

[11]Burnard, P., Haji Abd Rahim, H. T., Hayes, D. \& Edwards, D. (2007) A descriptive study of Bruneian student nurses' perceptions of stress. Nurse Educ Today., 27, 808-18. Epub 2007 Mar 26. http://dx.doi.org/10.1016/j.nedt.2006.11.002.

[12]Carlson, S., Kotze, W. J. \& Van Rooyen, D. (2003). Accompaniment needs of first year nursing students in the clinical learning $\begin{array}{llll}\text { environment. } & \text { Curationis., } & 26, & 30-9 .\end{array}$ http://dx.doi.org/10.4102/curationis.v26i2.778.

[13]Chan, C., So, W. \& Fong, D. (2009). Hong Kong Baccalaureate Nursing Students' Stress and Their Coping Strategies in Clinical Practice. Journal of professional nursing : official journal of the American Association of Colleges of Nursing, 25, 307-313. http://dx.doi.org/10.1016/j.profnurs.2009.01.018.

[14] Cheung, R. Y.-M. \& Au, T. K.-F. (2011). Nursing students' anxiety and clinical performance. The Journal of nursing education, 50, 286289. http://dx.doi.org/10.3928/01484834-20110131-08.

[15]Choi, Y., Abbott, T., Arthur, M. \& Hill, D. (2007). Towards a future wireless classroom paradigm. International Journal of Innovation and Learning, 4, 14-25. http://dx.doi.org/10.1504/IJIL.2007.011472.

[16]De Saintonge, D. M. \& Dunn, D. M. (2001). Gender and achievement in clinical medical students: a path analysis. Med Educ, 35, 1024-33. http://dx.doi.org/10.1046/j.1365-2923.2001.01043.x.

[17]Deary, I., Watson, R. \& Hogston, R. (2003). A longitudinal cohort study of burnout and attrition in nursing students. Journal of Advanced Nursing, 43, 71-81. http://dx.doi.org/10.1046/j.13652648.2003.02674.x.

[18] Elliot, A., Shell, M., Henry, K. \& Maeir, M. (2005). Achievement Goals, Performance Contingencies and Performance Attainment: An Experimental Test. Journal of Educational Psychology, 97, 630-640. http://dx.doi.org/10.1037/0022-0663.97.4.630. 
[19]Elliott, M. (2002). The clinical environment: a source of stress for undergraduate nurses. Aust J Adv Nurs., 20, 34-8.

[20]Floyd, J. (2010). Depression, Anxiety, and Stress Among Nursing Students and the Relationship to Grade Point Average. 3443001 Ed.D., Union University. Available: http://search.proquest.com/docview/854048417?accountid=14169http: //113md4hy6n.search.serialssolutions.com/

[21]Hamill, C. (1995). The phenomenon of stress as perceived by Project 2000 student nurses: a case study. Journal of Advanced Nursing, 21 528-536. http://dx.doi.org/10.1111/j.1365-2648.1995.tb02737.x.

[22]Hass, R. E., Nugent, K. E. \& Rule, R. A. (2004). The use of discriminant function analysis to predict student success on the NCLEX-RN. Journal of Nursing Education, 43, 440- 446.

[23]Hayden-Miles, M. (2002). Humor in clinical nursing education. J Nurs Educ., 41, 420-4.

[24]Hofer, M. (2007). Goal conflict and self-regulations: A new look at pupils' off-task behavior in the classroom. Educational Research Review, 2, 28-38. http://dx.doi.org/10.1016/i.edurev.2007.02.002.

[25]Hutchinson, T. L. \& Janiszewski Goodin, H. (2013). Nursing Studen Anxiety as a Context for Teaching/Learning. Journal of Holistic Nursing, 31, 19-24. http://dx.doi.org/10.1177/0898010112462067.

[26]Jimenez, C., Navia-Osorio, P. M. \& Diaz, C. V. (2010). Stress and health in novice and experienced nursing students. Journal of Advanced Nursing, 66, 442-455. http://dx.doi.org/10.1111/j.13652648.2009.05183.x.

[27]Jones, M. C. \& Johnston, D. W. (2000). Reducing distress in firs level and student nurses: a review of the applied stress management literature. Journal of Advanced Nursing, 32, 66-74 http://dx.doi.org/10.1046/j.1365-2648.2000.01421.x.

[28] Kaplan, H. I. \& Sadock, B. J. (2000). Learning Theory: Synopsis of Psychiatry: Behavioral Sciences/Clinical Psychiatry, Philadelphia, Lippincott Williams and Wilkins.

[29]Khater, W., Akhu-Zaheya, L. \& Shaban, I. (2014). Sources of Stress and Coping Behaviours in Clinical Practice among Baccalaureate Nursing Students. International Journal of Humanities and Socia Science, 4, 194-202.

[30]Killam, L. A., Mossey, S., Montgomery, P. \& Timmermans, K. E. (2013). First year nursing students' viewpoints about compromised clinical safety. Nurse Education Today, 33 475-480. http://dx.doi.org/10.1016/j.nedt.2012.05.010.

[31]Kim, K. H. (2003). Baccalaureate nursing students' experiences of anxiety producing situations in the clinical setting. Contemporary Nurse, 14, 145-155. http://dx.doi.org/10.5172/conu.14.2.145.

[32]Lambert, V. A. \& Lambert, C. E. (2001). Literature review of role stress/strain on nurses: an international perspective. Nursing \& Health Sciences, $\quad 3, \quad$ 161-172. http://dx.doi.org/10.1046/j.1442 2018.2001.00086.x.

[33]Lazarus, R. \& Folkman, S. (1984 ). Stress appraisal and coping, New York, Springer.

[34]Leblanc, V., Woodrow, S., Sidhu, R. \& Dubrowski, A. (2008). Examination stress leads to improvements on fundamental technical skills for surgery. Am J Surg, 196, 114-119. http://dx.doi.org/10.1016/j.amjsurg.2007.08.059.

[35]Luo, Y. \& Wang, H. (2009). Correlation research on psychological health impact on nursing students against stress, coping way and social support. Nurse Education Today, 29, 5-8. http://dx.doi.org/10.1016/j.nedt.2008.05.019.

[36]Mahat, G. (1998). Stress and Coping: Junior Baccalaureate Nursing Students in Clinical Settings. Nursing Forum, 33, 11-19. http://dx.doi.org/10.1111/j.1744-6198.1998.tb00976.x.

[37]Oberleitner, M. G., Broussard, A. B. \& Bourque, J. (2011). An Unintended Consequence of Simulation: A Case Report. Clinical Simulation in Nursing, 7, e35-e40. http://dx.doi.org/10.1016/j.ecns.2010.03.074.

[38] Oermann, M. H. \& Lukomski, A. P. (2001). Experiences of Students in Pediatric Nursing Clinical Courses. Journal for Specialists in Pediatric Nursing, 6, 65-72. http://dx.doi.org/10.1111/j.17446155.2001.tb00123.x.

[39]Pitt, V., Powis, D., Levett-Jones, T. \& Hunter, S. (2012). Factor influencing nursing students' academic and clinical performance and attrition: An integrative literature review. Nurse Education Today, 32 903-913. http://dx.doi.org/10.1016/j.nedt.2012.04.011.

[40]Pulido-Martos, M., Augusto-Landa, J. M. \& Lopez-Zafra, E. (2012) Sources of stress in nursing students: a systematic review of quantitative studies. International Nursing Review, 59, 15-25. http://dx.doi.org/10.1111/j.1466-7657.2011.00939.x.

[41] Robbins, S., et al. (2006). Unraveling the differential effects of motivational and skills, social, and self-management measures from traditional predictors of college outcomes. Journal of Educational
Psychology, 98, 598-616. http://dx.doi.org/10.1037/00220663.98.3.598.

[42] Shaban, I. A., Khater, W. A. \& Akhu-Zaheya, L. M. (2012). Undergraduate nursing students' stress sources and coping behaviours during their initial period of clinical training: A Jordanian perspective. Nurse Education in Practice, 12, 204-209. http://dx.doi.org/10.1016/j.nepr.2012.01.005.

[43] Sharif, F. \& Masoumi, S. (2005). A qualitative study of nursing student experiences of clinical practice. BMC Nursing, 4, 6. http://dx.doi.org/10.1186/1472-6955-4-6.

[44] Sheu, S., Lin, H. \& Hwang, S. (2002). Perceived stress and physiopsycho-social status of nursing students during their initial period of clinical practice: the effect of coping behaviors. International Journal of Nursing Studies, 39, 165-175. http://dx.doi.org/10.1016/S00207489(01)00016-5.

[45] Sheu, S., et al. (1997). The development and testing of perceived stress scale of clinical practice. Nursing Research, 5, 341-351.

[46] Singh, A., et al. (2013). A descriptive study of perceived stress among the North Indian nursing undergraduate students. Iranian Journal of Nursing \& Midwifery Research, 18, 340-342.

[47]Timmins, F. \& Kaliszer, M. (2002). Aspects of nurse education programmes that frequently cause stress to nursing students-Fact finding sample survey. Nurse Education Today, 22, 203-211. http://dx.doi.org/10.1054/nedt.2001.0698.

[48] Trautwein, U., et al. (2006). Tracking, Grading, and student motivation: Using group composition and status to predict selfconcept and interest in ninth-grade Mathematics. Journal of Educational Psychology, 98, 788-806. http://dx.doi.org/10.1037/0022$\underline{0663.98 .4 .788}$

[49] Tully, A. (2004). Stress, sources of stress and ways of coping among psychiatric nursing students. Journal of Psychiatric and Mental Health Nursing, 11, 43-47. $\quad$ http://dx.doi.org/10.1111/j.13652850.2004.00682.x.

[50]Was, C., Woltz, D. \& Drew, C. (2006). Evaluating character education programs and missing the target: A critique of existing research. Educational Research Review, 1, 148-156. http://dx.doi.org/10.1016/j.edurev.2006.08.001.

[51]Watson, R., Deary, I., Thompson, D. \& Li, G. (2008). A study of stress and burnout in nursing students in Hong Kong: A questionnaire survey. International Journal of Nursing Studies, 45, 1534-1542. http://dx.doi.org/10.1016/j.ijnurstu.2007.11.003.

[52] Yucha, C., Kowalski, S. \& Cross, C. (2009). Student stress and academic performance: Home hospital program. Faculty Publications. Paper 3. Accessed 31, Oct.2011 [Online]. Available: http://digitalcommons.library.unlv.edu/nursing_fac_articles/3 [Accessed 31, Oct. 2011]. 